\title{
APTIDÃO FÍSICA RELACIONADA AO DESEMPENHO MOTOR NAS SÉRIES INICIAIS E A INTERVENÇÃO DO PROFISSIONAL DE EDUCAÇÃO FÍSICA
}

\author{
PHYSICAL APTITUDE RELATED MOTOR PERFORMANCE IN INITIAL GRADES \\ AND THE INTERVENTION OF THE PHYSICAL EDUCATION PROFESSIONAL
}

\section{Debora Tornquist ${ }^{1 *}$, Luciana Tornquist ${ }^{2^{*}}$, Miriam Beatris Reckziege $\mathbf{l}^{3^{*}}$, Cézane Priscila Reuter ${ }^{4}$, Miria Suzana Burgos ${ }^{5^{*}}$}

\author{
1'debora.tornquist@bol.com.br, ${ }^{2}$ luciana.tornquist@yahoo.com.br, ${ }^{3}$ miriam@unisc.br, ${ }^{4}$ cpreuter@hotmail.com, ${ }^{5} \mathrm{mburgos} @$ unisc.br \\ *Universidade de Santa Cruz do Sul (UNISC)
}

\section{RESUMO}

Objetivo: Verificar se existem diferenças nos níveis de desempenho motor entre escolares de séries iniciais que possuem aulas ministradas por um profissional de Educação Física (escolas municipais) e as que têm aulas ministradas por um professor unidocente (escolas estaduais). Métodos: São sujeitos deste estudo 488 escolares de séries iniciais de 12 escolas do município de Santa Cruz do Sul (RS). Os componentes de desempenho motor avaliados foram a agilidade, velocidade e força de membros superiores e inferiores. Resultados: Os resultados demonstram que, independentemente da rede de ensino e da presença do profissional de Educaçấo Física, os resultados ficaram abaixo dos índices desejados. As escolas que não possuem professor de Educaçáo Física apresentaram os piores resultados nas avaliaçôes, com exceção da força de membros superiores, para ambos os sexos, e velocidade, para o sexo feminino. Diferenças estatisticamente significativas só foram encontradas no teste de agilidade para o sexo masculino, com maior percentual de resultados insatisfatórios por aluno da rede estadual, e na avaliação da força de membros superiores, também para o sexo masculino, porém, com maior percentual de escolares da rede municipal com resultados abaixo do recomendável. Conclusão: Nossos resultados demonstram que, independentemente do profissional atuante nas séries iniciais, o desempenho motor dos escolares apresenta-se abaixo dos índices desejáveis, o que pode indicar que a Educação Física escolar está deixando de trabalhar valências importantes no desenvolvimento dos escolares e precisa ser revista e reformulada, a fim de proporcionar um nível satisfatório de esforços físicos, trazendo o máximo de benefícios aos alunos.

Palavras-chave: educação física e treinamento; aptidão física; docentes.

\section{ABSTRACT}

Objective: To verify if there are differences in the levels of motor performance between students of the initial grades that have classes taught by a Physical Education teacher (municipal schools) and those whose lessons are taught by a schoolmaster (state schools). Methods: The subjects of this study are 488 schoolchildren from the initial grades of 12 schools in the municipality of Santa Cruz do Sul (RS). The components of motor performance assessed were agility, speed and strength of upper and lower limbs. Results: Results show that, regardless of the school system and the presence of a Physical Education teacher, the results were below desired levels. Schools that do not have a Physical Education teacher presented the worst results in the assessments, with the exception of upper limb strength, for both genres, and speed, for females. Statistically significant differences were only found in the agility test for males, with a higher percentage of unsatisfactory results by state school students; and in the assessment of the strength of the upper limbs, also for males, however, with a higher percentage of schoolchildren from municipal schools with results below recommended. Conclusion: Our results demonstrate that, regardless of the 
Tornquist D., Tornquist L., Reckziegel M. B., Reuter C. P., Burgos M. S.

professional working in the initial grades, the motor performance of schoolchildren remains below desirable levels, which may indicate that the Physical Education classes are not focusing on relevant variables in the development of schoolchildren and it needs to be reviewed and reformulated in order to provide a satisfactory level of physical effort, bringing maximum benefits to students.

Keywords: physical education and training; physical fitness; faculty.

\section{Introdução}

De acordo com o art. $26, \$ 3^{\circ}$, da Lei de Diretrizes e Bases da Educação Nacional, no 9.394/1996, a Educação Física é um componente curricular obrigatório da educação básica, sendo facultativa apenas a alunos que cumpram jornada de trabalho igual ou superior a seis horas, tenham mais de trinta anos de idade, estejam prestando serviço militar inicial ou, em situação similar, estejam obrigados à prática da educação física ${ }^{1}$. No entanto, apesar de determinar a obrigatoriedade da Educaçáo Física tanto na educaçáo infantil quanto no ensino fundamental e médio, a lei náo deixa claro quem deve ministrar as aulas dessa disciplina².

No estado do Rio Grande do Sul está em vigor a Lei $n^{\circ} 8.747 / 88$, que trata da gratificação a professores que exercerem unidocência nas séries iniciais nas escolas da rede estadual de ensino ${ }^{4}$. A unidocência pode ser entendida como a união de todos os conteúdos ministrados por um único professor. Este profissional deveria buscar uma atualização constante em todas as áreas, entre elas a Educação Física, porém muitos professores unidocentes não demonstram interesse e/ou afinidade por esta disciplina, que acaba, por vezes, sendo deixada de lado $^{4}$.

Martins e Felker ${ }^{5}$ defendem a necessidade de se oferecer aos alunos das séries iniciais uma Educação Física de qualidade, declarando que o profissional desta disciplina está mais preparado para ministrar as aulas, pois este estudou de 4 a 5 anos as especificidades desta, enquanto na formação do magistério, os estudos que contemplam a Educação Física são mínimos. Para Etchepare, Pereira e Zinn ${ }^{6}$, a falta de profissionais para trabalhar a cultura corporal nas séries iniciais faz que os alunos criem a ideia de que Educação Física é apenas "jogar bola" e ingressem nos anos finais com este conceito. Os autores ressaltam que por causa disso encontramos alunos nas séries finais do ensino fundamental com inúmeras limitaçóes em motricidade fina e ampla.

Para Meurer e Pereira ${ }^{7}$, a Educação Física nas séries iniciais exige do professor um grande repertório de saberes adquiridos na educação formal e informal e pela experiência. Para que seja realizada uma aula de Educação Física de qualidade nestas séries, é necessário o envolvimento de toda a escola, buscando oferecer condiçóes para a realização das atividades e também que os professores tenham consciência da importância da disciplina para o desenvolvimento harmônico dos alunos. Os autores destacam que durante entrevistas, observaçóes, participaçôes em reunióes pedagógicas e atuação prática em duas turmas de séries iniciais em uma escola estadual de um bairro na cidade de Santa Maria (RS), perceberam que a Educação Física nas séries iniciais vem sendo negligenciada por muitos professores, sendo a formação deficitária e a desvalorização da disciplina no meio escolar aspectos importantes a serem considerados.

Freire $^{8}$ aponta duas linhas de defesa em relação a quem deve ministrar as aulas de Educação Física. A primeira, na qual defende a inclusão de um professor formado em Educação Física, coloca que a escola possui um conjunto de disciplinas voltadas para a formação intelectual e outra que reúne os conteúdos voltados para a formação corporal. Nessa concepção, torna-se difícil as escolas de formação de professores se transformarem para capacitar os profissionais de ensino a ministrar aulas nas diferentes áreas do conhecimento. $\mathrm{Na}$ segunda, na qual defende a permanência do professor regente, observa que pode ser melhor para a criança o contato com um único professor, devido a uma possível diminuição na fragmentação do conhecimento.

Segundo Santos ${ }^{9}$, a aptidão física vem sendo alvo de estudos há bastante tempo, sendo que com a diminuição da prática de atividades físicas entre a população escolar, a aptidão física se converteu em motivo de grande interesse para profissionais da área da saúde. A aptidão física, na atualidade, divide-se em dois aspectos: ligados à saúde e ao desempenho motor. $\mathrm{O}$ primeiro refere-se a componentes que propiciem desenvolver as atividades do cotidiano com vigor e proteção às doenças crônicodegenerativas. $\mathrm{O}$ segundo relaciona-se a aspectos de habilidades motoras que contribuem para o sucesso em atividades esportivas e diárias ${ }^{10}$. $\mathrm{O}$ desempenho motor pode ser entendido como um conjunto de capacidades motoras importantes nas exigências do cotidiano, como também nas diversas especificidades do esporte ${ }^{11}$.

Guedes ${ }^{12}$ considera a infância e a adolescência como um período em que o organismo encontra-se especialmente sensível à influência de fatores ambientais e comportamentais, além das implicaçóes de cunho fisiológico relacionadas aos aspectos de maturação biológica. Por isso, destaca que o acompanhamento dos índices de desempenho motor de crianças e adolescentes pode contribuir de forma decisiva na tentativa de promover 
a prática de atividades físicas no presente e para toda a vida. Além disso, a aptidão física adquirida na infância e adolescência tende a perdurar até a fase adulta ${ }^{13}$.

Arruda et al. ${ }^{14}$ colocam que programas de atividade física escolar apresentam uma certa carência quanto ao conhecimento das necessidades reais dos indivíduos envolvidos, tornando difícil o direcionamento do trabalho que deve ser desenvolvido. Desta forma, avaliaçóes que busquem descrever as características de crescimento e de desempenho motor e suas interaçóes constituem importantes indicadores, podendo atuar na prevenção primária e na promoção da saúde ${ }^{15}$.

Desta forma, este estudo objetiva verificar se existem diferenças nos níveis de desempenho motor entre escolares de séries iniciais que possuem aulas ministradas pelo profissional de Educação Física (escolas municipais) e aqueles que têm aulas ministradas pelo professor unidocente (escolas estaduais).

\section{Métodos}

O presente estudo foi desenvolvido a partir do banco de dados da pesquisa "Saúde e Estilo de Vida na Escola e na Família: no meio urbano e rural de Santa Cruz do Sul”, que avaliou 1578 escolares do município, entre 7 e 17 anos. Para o cálculo do tamanho da amostra foi utilizada a fórmula de Gil e Nea Research Division, citada por Christensen ${ }^{16}$, com nível de significância de $5 \%$. Do total da população estratificada (em zona rural e urbana, centro e periferia, norte, sul, leste e oeste), foi calculado o número de escolas e escolares que participaram do estudo. Estimou-se então uma amostra de aproximadamente 400 sujeitos, representativa do município. Porém, a avaliação foi estendida a um número maior de sujeitos, escolhidos aleatoriamente. Todos os avaliados tiveram o Termo de Consentimento Livre e Esclarecido assinado pelos pais ou responsáveis, e a pesquisa foi aprovada pelo Comitê de Ética em Pesquisa com Seres Humanos da Universidade de Santa Cruz do Sul (CEP - UNISC - processo 4913-2007).

Para a realização do presente estudo, foi realizado um recorte da amostra da pesquisa anteriormente citada, selecionando apenas os escolares de séries iniciais de doze escolas, seis municipais e seis estaduais, do município de Santa Cruz do Sul (RS). Desta forma, constituem-se sujeitos deste estudo 488 escolares, com média de idade de 9,11 $( \pm 1,54)$ anos. A média de idade entre os escolares da rede municipal, que contam com aulas ministradas pelo profissional de Educação Física, é de 9,38 $( \pm 1,71)$ anos, sendo $9,37( \pm 1,78)$ para o sexo masculino e 9,40 $( \pm 1,62)$ para o feminino. Entre os alunos da rede estadual, que possuem aulas ministradas pelo professor regente, a média de idade é de $8,90( \pm 1,71)$ anos, sendo de 9,02 $( \pm 1,39)$ para o sexo masculino e $8,77( \pm 1,32)$ para o feminino. Na Tabela 1 são apresentadas as características dos sujeitos. A amostra é composta por 276 escolares da rede estadual de ensino e 212 escolares da rede municipal. Observa-se ainda que 53,3\% dos escolares são do sexo masculino, 58,0\% da periferia e 67,6\% pertencem às classes econômicas mais baixas $(\mathrm{C}, \mathrm{D}$ e E). A classificação do nível socioeconômico foi realizada a partir do critério de classificação $\mathrm{ABEP}^{17}$.

Tabela 1: Caracterização dos sujeitos

\begin{tabular}{lc}
\hline Sexo & n (\%) \\
\hline Femino & $228(46,7)$ \\
Masculino & $260(53,3)$ \\
\hline Rede de Ensino & \\
\hline Estadual & $276(56,6)$ \\
Municipal & $212(43,4)$ \\
\hline Zona & \\
\hline Centro & $99(20,3)$ \\
Periferia & $283(58,0)$ \\
Rural & $106(21,7)$ \\
\hline Classe Econômica & \\
\hline A1, A2 & $6(1,2)$ \\
B1, B2 & $152(31,2)$ \\
C, D, E & $330(67,6)$ \\
\hline
\end{tabular}

As avaliaçóes eram realizadas em diferentes dias para cada escola, no próprio ambiente escolar, sendo que os escolares realizavam todas as avaliaçooes em um único dia, de modo individual. Os testes de desempenho motor foram realizados e classificados conforme o Manual PROESP-BR ${ }^{18}$. O teste do quadrado foi utilizado para avaliar a agilidade dos escolares. Neste teste, utiliza-se um quadrado desenhado em solo com 4 metros de lado e quatro cones demarcado suas pontas, no qual o aluno deve realizar o seguinte percurso ao sinal do avaliador: saindo da linha de partida, deverá deslocar-se até o próximo cone em direçáo diagonal, correr em direção ao cone à sua esquerda e se deslocar para o cone em diagonal (atravessar o quadrado em diagonal); finalmente, correr em direção ao último cone, que corresponde ao ponto de partida. $\mathrm{O}$ aluno deverá tocar com uma das máos cada um dos cones que demarcam o percurso, sendo cronometrado o tempo que o aluno levou para realizar o percurso. Sáo realizadas duas tentativas, sendo registrado o melhor tempo de execução.

Para mensurar a velocidade dos escolares foi realizado o teste de corrida de 20 metros. Para a realizaçáo deste teste, é utilizada uma pista de $20 \mathrm{~m}$ de comprimento demarcada com três linhas paralelas no solo: a primeira é denominada linha de partida; a segunda, a 20 m de distância da linha de partida, é denominada linha de cronometragem; a terceira, marcada a um metro 
da linha de cronometragem, é a linha de chegada. O aluno é orientado a partir da linha de partida e deslocarse o mais rápido possível em direção à linha de chegada, sendo anotado o tempo entre a linha de partida e a de cronometragem. A terceira linha serve como referência de chegada para o aluno na tentativa de evitar que ele inicie a desaceleraçáo antes de cruzar a linha de cronometragem. Utilizaram-se dois cones para a sinalização da primeira e terceira linhas.

A força dos membros inferiores foi avaliada através do teste de salto horizontal, no qual uma trena é fixada ao solo, perpendicularmente à linha de partida, sendo que o ponto zero da trena situa-se sobre a linha de partida. O avaliado coloca-se atrás da linha, com os pés paralelos, ligeiramente afastados, joelhos semiflexionados e tronco ligeiramente projetado para frente. Ao sinal, o aluno deverá saltar a maior distância possível aterrissando com os dois pés simultaneamente. Serão realizadas duas tentativas, registrando-se o melhor resultado.

Já a força dos membros superiores foi mensurada através do teste de arremesso da medicine ball $(2 \mathrm{Kg})$. Nesta avaliação, a trena é fixada no solo perpendicularmente à parede. $\mathrm{O}$ ponto zero da trena é fixado na parede. $\mathrm{O}$ aluno senta-se com os joelhos estendidos, as pernas unidas e as costas completamente apoiadas à parede, segura a medicine ball próxima ao peito, com os cotovelos flexionados. Ao sinal do avaliador, o aluno deverá lançar a bola o mais distante possível, mantendo as costas apoiadas na parede. A distância do arremesso será registrada a partir do ponto zero até o local em que a bola tocou o solo pela primeira vez. Serão realizados dois arremessos, registrando-se o melhor resultado.

Para análise estatística dos dados foi utilizado o software SPSS for Windows, versão 20.0., através de análise descritiva, frequência e percentual. Utilizou-se o teste de qui-quadrado para variáveis categóricas, sendo consideradas diferenças significativas $(\mathrm{p}<0,05)$ com um intervalo de confiança de 95\%.

Reconhece-se como limitação do nosso estudo o fato de que não foram observados os conteúdos ministrados, objetivos propostos e nem métodos utilizados em cada aula de Educação Física, bem como a frequência semanal e duração de cada aula. Assim como não foi controlada a pratica de exercícios físicos fora do período escolar, como clubes esportivos em turno oposto; fatores estes que podem interferir nos resultados.

\section{Resultados}

Na Tabela 2 são apresentados os resultados (frequência e percentual) das avaliaçóes de desempenho motor dos escolares nos testes de agilidade, velocidade e força de membros inferiores e superiores, estratificados por sexo e por rede de ensino. Observa-se que diferenças estatisticamente significativas foram encontradas entre os grupos no teste de agilidade para o sexo masculino, com maior percentual de resultados insatisfatórios por alunos da rede estadual, e na avaliaçáo da força de membros superiores, também para o sexo masculino, porém com maior percentual de escolares da rede municipal com resultados abaixo do recomendável.

\section{Discussão}

O principal objetivo de nosso estudo foi verificar se existem diferenças nos níveis de desempenho motor entre escolares de séries iniciais que possuem aulas ministradas pelo profissional de Educação Física e aqueles que têm aulas ministradas pelo professor unidocente. Observamos que diferenças estatisticamente significativas entre os grupos só ocorreram no teste de agilidade para o sexo masculino, com maior percentual de resultados insatisfatórios por alunos da rede estadual, e na força de membros superiores, também para o sexo masculino, com maior percentual de escolares da rede municipal com resultados abaixo do recomendável. No entanto, as escolas estaduais alcançaram, com exceção da força de membros superiores, para ambos os sexos, e da velocidade, para o sexo feminino, maiores percentuais de índices insatisfatórios. Não foram encontrados na literatura estudos que comparassem o nível de desempenho motor de escolares com a assistência do profissional de Educação Física.

Ao analisarmos cada valência avaliada, constatamos que a força de membros superiores foi a que obteve melhores resultados dos avaliados, com menor percentual de índices insatisfatórios. Indo de encontro aos achados do estudo de Luguetti et al. ${ }^{19}$, no qual tanto o sexo feminino quanto o masculino obtiveram seu principal percentual na zona recomendada, com pequena superioridade do sexo masculino. Diferentemente, um estudo de Borges et al. ${ }^{20}$, realizado em São Paulo, encontrou níveis muito baixos no teste de medicine ball, onde tanto os meninos como as meninas avaliados foram classificados, em sua maioria, nas classificações de pior desempenho. Já em um estudo de Verardi et al. ${ }^{15}$, a maioria dos meninos alcançou a classificação "muito bom" ou "bom" $(61,77 \%)$, enquanto apenas $34,62 \%$ das meninas se enquadraram em uma destas faixas.

Com relação ao teste do salto horizontal (força de membros inferiores), os escolares apresentaram, em ambos os sexos e ambas as redes de ensino, maior percentual de índices abaixo do recomendável. Barbosa et al. ${ }^{21}$ encontraram nos resultados deste teste os piores desempenhos entre todos os testes de aptidão por eles aplicados. Do mesmo modo, Luguetti et al. ${ }^{19}$, em um 
Tabela 2: Desempenho motor dos escolares, estratificado por sexo e rede de ensino

\begin{tabular}{|c|c|c|c|c|c|c|}
\hline & & & \multicolumn{2}{|c|}{ Classificação } & \multirow[b]{2}{*}{ Total } & \multirow[b]{2}{*}{$\mathbf{p}$} \\
\hline & & & $\begin{array}{c}\text { Insatisfatório* }^{*} \\
\text { n (\%) } \\
\end{array}$ & $\begin{array}{c}\text { Satisfatório** }^{* *} \\
\text { n (\%) }\end{array}$ & & \\
\hline \multirow{6}{*}{$\frac{\frac{\pi}{\tilde{\pi}}}{\frac{\pi}{0}}$} & \multirow{3}{*}{ 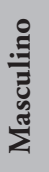 } & Escolas Estaduais & $129(90,2)$ & $14(9,8)$ & $143(100,0)$ & \multirow{3}{*}{0,008} \\
\hline & & Escolas Municipais & $92(78,6)$ & $25(21,4)$ & $117(100,0)$ & \\
\hline & & Total & $221(85,0)$ & $39(15,0)$ & $260(100,0)$ & \\
\hline & \multirow{3}{*}{ ¿ } & Escolas Estaduais & $119(89,5)$ & $14(10,5)$ & $133(100,0)$ & \multirow{3}{*}{0,054} \\
\hline & & Escolas Municipais & $77(81,1)$ & $18(18,9)$ & $95(100,0)$ & \\
\hline & & Total & $196(86,0)$ & $32(14,0)$ & $228(100,0)$ & \\
\hline \multirow{6}{*}{$\begin{array}{l}\frac{0}{\tilde{g}} \\
\frac{\pi}{0} \\
\frac{0}{0} \\
\end{array}$} & \multirow{3}{*}{ 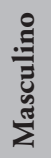 } & Escolas Estaduais & $131(91,6)$ & $12(8,4)$ & $143(100,0)$ & \multirow{3}{*}{0,168} \\
\hline & & Escolas Municipais & $102(87,2)$ & $15(12,8)$ & $117(100,0)$ & \\
\hline & & Total & $233(89,6)$ & $27(10,4)$ & $260(100,0)$ & \\
\hline & \multirow{3}{*}{ 莣 } & Escolas Estaduais & $123(92,5)$ & $10(7,5)$ & $133(100,0)$ & \multirow{3}{*}{0,347} \\
\hline & & Escolas Municipais & $90(94,7)$ & $5(5,3)$ & $95(100,0)$ & \\
\hline & & Total & $213(93,4)$ & $15(6,6)$ & $228(100,0)$ & \\
\hline \multirow{6}{*}{ 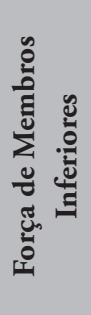 } & \multirow{3}{*}{ 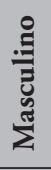 } & Escolas Estaduais & $123(86,0)$ & $20(14,0)$ & $143(100,0)$ & \multirow{3}{*}{0,110} \\
\hline & & Escolas Municipais & $93(79,5)$ & $24(20,5)$ & $117(100,0)$ & \\
\hline & & Total & $216(83,1)$ & $44(16,9)$ & $260(100,0)$ & \\
\hline & \multirow{3}{*}{ 晜 } & Escolas Estaduais & $114(85,7)$ & $19(14,3)$ & $133(100,0)$ & \multirow{3}{*}{0,223} \\
\hline & & Escolas Municipais & $77(81,1)$ & $18(18,9)$ & $95(100,0)$ & \\
\hline & & Total & $191(83,8)$ & $37(16,2)$ & $228(100,0)$ & \\
\hline \multirow{6}{*}{ 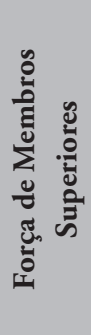 } & \multirow{3}{*}{ 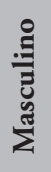 } & Escolas Estaduais & $47(32,9)$ & $96(67,1)$ & $143(100,0)$ & \multirow{3}{*}{0,020} \\
\hline & & Escolas Municipais & $54(46,2)$ & $63(53,8)$ & $117(100,0)$ & \\
\hline & & Total & $101(38,8)$ & $159(61,2)$ & $260(100,0)$ & \\
\hline & \multirow{3}{*}{ : } & Escolas Estaduais & $68(51,1)$ & $65(48,9)$ & $133(100,0)$ & \multirow{3}{*}{0,117} \\
\hline & & Escolas Municipais & $57(60,0)$ & $38(40,0)$ & $95(100,0)$ & \\
\hline & & Total & $125(54,8)$ & $103(45,2$ & $228(100,0)$ & \\
\hline
\end{tabular}

*Insatisfatório $=$ muito fraco $/$ fraco/razoável.

${ }^{* *}$ Satisfatório $=$ bom/muito bom/excelente.

estudo na região centro-oeste de São Paulo, encontraram a maior parte dos escolares na classificação "ruim". Diferentemente, um estudo com escolares na cidade de Carneirinhos (MG), encontrou, em ambos os sexos, principais resultados na zona "muito bom" ou "bom"15. Cruz $^{22}$ alerta para o fato de que a experiência de movimentos que a criança ou adolescente adquiriram é um forte fator para uma boa capacidade de salto. Além disso, o salto também depende de fatores biomecânicos, como o tamanho corporal, e um maior comprimento das pernas que gera uma alavanca mais eficiente para a execução do movimento de saltar ${ }^{23}$.

No teste do quadrado, utilizado para mensurar o nível de agilidade dos escolares, também em ambas as redes de ensino e para ambos os sexos, a maioria dos avaliados teve sua classificação na faixa insatisfatória. Barbosa et al. ${ }^{21}$ encontraram resultados no teste do quadrado concentrados na faixa "razoável" ou "fraco". Segundo Miyasike-da-Silva et al., esta é uma valência essencial nas tarefas do cotidiano, como andar desviando de pessoas ou obstáculos, locomover-se carregando objetos ou deslocar-se rapidamente ${ }^{24}$.

No teste de 20 metros (velocidade), também a grande maioria ficou entre os índices insatisfatórios. Verardi et al..$^{15}$ encontrou resultados semelhantes em um estudo na cidade de Carneirinho (MG), onde os principais índices de classificação ficaram nas faixas "razoável", "muito fraco" e "fraco", tanto para o sexo feminino $(84,62 \%)$ 
quanto para o masculino $(94,12 \%)$, diferentemente do resultado encontrado no estudo de Palandrani Júnior ${ }^{25}$, realizado com alunos de uma escola de Campinas (SP), na qual os meninos apresentaram desempenho razoável e as meninas obtiveram resultados classificados como bons. Já Lucca e Guerra ${ }^{26}$ encontraram, na cidade de Ipatinga (MG), índices abaixo do desejado entre 43\% das meninas e $36 \%$ dos meninos avaliados.

De uma forma geral, observamos em nosso estudo que tanto os alunos com aula ministrada por profissional habilitado quanto os que têm o professor regente, de ambos os sexos, apresentaram elevados percentuais de índices insatisfatórios em todas as valências avaliadas. Gallahue e Osmun ${ }^{27}$ citam que diferenças de desempenho motor podem ser influenciadas por três fatores: individual (biologia), ambiental (experiência) e da tarefa (físicos/mecânicos). Já Verardi et al. ${ }^{15}$ afirmam que para a melhora dos índices nos aspectos de desempenho motor em escolares faz-se necessária a intervenção do professor de Educação Física, que deve destinar parte da programação de sua aula para o desenvolvimento dessas valências.

Nossos resultados podem ser um indicativo do exposto no estudo de Guedes e Guedes ${ }^{28}$, que avaliou 144 aulas de Educaçáa Física em 15 escolas diferentes de Londrina (PR) e constatou que os estímulos recebidos durante as aulas são insuficientes para provocar adaptaçóes positivas no organismo dos escolares. Os esforços físicos realizados pelos alunos no decorrer das aulas foram, em sua maioria, de baixa ou muito baixa intensidade, inviabilizando um aprimoramento da aptidão física destes alunos. Além disso, os pesquisadores constataram que por aproximadamente $50 \%$ da aula os alunos permanecem inativos, desprendendo, deste tempo, a administração e organização das atividades, bem como aguardando sua vez de realizá-las, semelhante aos achados de Carniel e Toigo ${ }^{29}$, que verificaram as aulas de Educação Física em cinco escolas particulares de Porto Alegre (RS) e observaram que $44,9 \%$ do tempo de aula foi gasto com instruçáo dos alunos, $8,6 \%$ com administração das atividades e apenas $29,9 \%$ com aprendizagem ativa dos alunos.

O mesmo ocorre no estudo de Santos', que ao observar aulas de uma escola de Porto Alegre (RS), constatou que, durante os 45 minutos disponibilizados para a Educação Física, $41 \%$ do tempo os alunos permaneciam em pé, $27 \%$ caminhando, $20 \%$ sentados e apenas 9\% correndo.

Ao analisar as características das aulas de Educação Física de quatro escolas de Curitiba (PR), Hino, Reis e Añez ${ }^{30}$ observaram que $45,5 \%$ do tempo de aula os alunos permaneciam em pé, $26,3 \%$ caminhando, $17,9 \%$ sentados, $1,5 \%$ deitados e apenas $8,67 \%$ sendo muito ativos. Com relação aos professores, os autores observaram que em $37,9 \%$ do tempo de aula estes passavam observando e $37,5 \%$ do tempo realizando atividades não pertinentes aos conteúdos da aula.

Resultados muito semelhantes também foram encontrados em estudo no Texas, EUA, onde em apenas $8,5 \%$ do tempo total da aula de Educaçáo Física os alunos permaneciam em atividades de moderada ou vigorosa intensidade, em $23,3 \%$ em atividades de baixa intensidade e $68,1 \%$ inativos $^{31}$. Em um estudo realizado em Israel, em apenas 39\% do tempo das aulas avaliadas os alunos permaneceram em atividades moderadas ou vigorosas 32 .

Moroz $^{33}$ realizou estudo no município de Alvorada (RS) e buscou verificar a qualidade das aulas ministradas. Segundo o autor, apenas $17 \%$ do tempo de aula era destinado à realização das atividades planejadas e 45\%, atividades livres ou descontextualizadas. O tempo gasto com espera pelos alunos para realizar as atividades foi de $13 \%, 14 \%$ de instrução e $11 \%$ administração das atividades.

Embora os estudos citados não sejam realizados com escolares dos anos iniciais do ensino fundamental, estes demonstram que as aulas de Educação Física, mesmo quando ministradas por um profissional habilitado, estáo deixando uma lacuna no desenvolvimento destes escolares. Sabemos que o tempo relativamente curto das aulas, o elevado número de alunos nas turmas e a falta de materiais e de locais apropriados, especialmente nas escolas públicas, são grandes barreiras a serem derrubadas pelos professores. Entretanto, a Educação Física escolar deve ser repensada e reestruturada para que supra as necessidades de aprendizagem motora de nossos alunos, bem como proporcione um nível satisfatório de esforços físicos, capazes de proporcionar adaptaçóes positivas no organismo destes alunos. Nessa direçấo Nemet, Pantanowitz e Eliakim ${ }^{32}$ afirmam que buscar melhorar as aulas de educação física é um fator primordial para a promoção da saúde entre os escolares e um importante meio de prevenção da obesidade infantil.

Betti e Zulliani ${ }^{34}$ ressaltam que é importante proporcionar aos alunos oportunidades e realização de jogos, esportes, atividades rítmicas/expressivas, lutas e artes marciais, ginástica e prática da atividade física, com a exploração das variaçóes desses conteúdos, principalmente nas séries iniciais. Nesta fase, é fundamental considerar a atividade corporal como um elemento da vida infantil, sendo a estimulação adequada e diversificada essencial para isso. Para Silva Filho e Pereira ${ }^{2}$, é fundamental o professor ter consciência das características, necessidades e interesses de seus alunos para que, a partir desse diagnóstico, elabore estratégias e proponha atividades que favoreçam o alcance de seus objetivos, para que não se coloque em dúvida o processo de ensino e aprendizagem. 
Silva e Sampaio ${ }^{35}$ ressaltam a importância de que os benefícios dos jogos no ambiente escolar não se referem a uma perspectiva recreacionista, baseada apenas em "deixar as crianças brincarem", mas aos jogos enquanto conteúdo da Educação Física, entendidos como conhecimento da Cultura Corporal do Movimento, que a partir das necessidades dos alunos são planejados, organizados, sistematizados e desenvolvidos didaticamente. $\mathrm{O}$ autor ainda coloca que o jogo recreacionista, o deixar brincar, também contribui para o desenvolvimento da criança em outros contextos, mas não careceria de um profissional para acompanhá-lo, nem mesmo ser parte do componente curricular, caso fosse desenvolvido nesta perspectiva.

Com relação a quem deve ministrar as aulas de Educação Física nas séries iniciais, ao investigar 27 docentes de escolas municipais, estaduais e particulares da cidade de Santa Maria (RS) que ministram aulas de Educação Física nas séries iniciais do ensino fundamental, Etchepare, Pereira e Zinn ${ }^{6}$ constataram que apenas três professores eram formados em Educação Física e 24 professores possuíam formação de Magistério e/ ou Pedagogia. Destes, 59,25\% afirmaram que tiveram orientação de como trabalhar com Educação Física, porém a maioria coloca que esta orientação é um tanto teórica e pouco aplicável na prática escolar; $22,22 \%$ dos professores disseram ter tido pouca orientaçáo, o que dificulta a sua prática com o alunado; e 14,81\% dos professores não tiveram nenhuma orientação. Ainda, 93,75\% dos docentes entrevistados acham importante a atuação do profissional de Educação Física e acreditam ser este o profissional mais preparado para trabalhar o desenvolvimento físico e motor da criança, pois possui maior embasamento teórico e prático; e 6,25\% dos professores entrevistados acham-na importante em parte, pois consideram que esta atuação deveria ser um assessoramento ao professor de classe, que conhece e convive mais com os alunos.

Em estudo de Guirra ${ }^{36}$, realizado no estado do Mato Grosso por meio de entrevistas com professoras unidocentes em duas escolas públicas de educação infantil, algumas professoras alegaram que achavam importante a presença de um profissional especializado para as atividades de trabalho corporal, uma vez que acreditavam que sua formação, na graduação e pós-graduaçáo, não contemplava conhecimentos sobre a área do movimento humano e suas especificidades na infância. Em outro estudo, com seis professoras unidocentes na cidade de Santa Maria (RS), todas as professoras entrevistadas julgam ser o licenciado em Educação Física o profissional que deve trabalhar com os alunos das séries iniciais, alegando não ter preparação durante o curso de pedagogia para ministrarem estas aulas. $\mathrm{O}$ estudo cita que todas as professoras reconhecem a importância que a Educação Física desempenha nas séries iniciais, mas citam como dificuldades para desenvolver o conteúdo a falta de recursos físicos e materiais e de preparação para planejamento das aulas, sendo que os conteúdos trabalhados por estas professoras unidocentes estão de acordo com o referencial teórico da área, mas com pouca variabilidade, desfavorecendo o processo de ensino e aprendizagem $^{37}$.

Darido ${ }^{38}$ constatou em seu estudo que as professoras unidocentes aplicam nas aulas, atividades baseadas em suas experiências anteriores que geralmente implicam em deixar os alunos jogarem livremente, e ainda, muitas vezes, apenas se os alunos permanecerem comportados, tratando as aulas de Educação Física como uma premiaçáo. Ainda em seu estudo, constata que tanto as professoras unidocentes quanto as coordenadoras pedagógicas e diretoras entendem ser o profissional de Educação Física o mais bem preparado para assumir a responsabilidade de ministrar as aulas dessa disciplina.

No município de Várzea Grande (MG), 12 escolas públicas foram investigadas, avaliando-se um total de 58 professores unidocentes. $\mathrm{O}$ estudo constatou que destes, $22 \%$ dos afirmaram não ministrar aulas de Educação Física, embora seja garantido em lei o direito do aluno a estas aulas em toda a educaçáo básica. Referente aos conteúdos, entre os unidocentes que ministram as aulas, $82 \%$ dizem realizar aulas de recreaçáo e $60 \%$, jogos. Perguntados sobre as contribuiçóes das aulas para o desenvolvimento do aluno, $33 \%$ citaram a socialização. Ao serem questionados se receberam durante sua formação subsídio para ministrar as aulas de Educação Física, 46 professores responderam negativamente, e 38 disseram não sentir-se seguros para ministrar a disciplina. Questionados sobre a ausência do profissional de Educação Física, nas principais respostas os professores dizem não concordar por não estarem preparados para ministrar estas aulas e que a aula ministrada pelo profissional de Educação Física pode contribuir mais efetivamente na formação dos alunos ${ }^{35}$.

Também no estudo de Pereira ${ }^{39}$, que investigou escolas públicas do município de Santo André (SP), os professores unidocentes pesquisados acreditavam que $\mathrm{o}$ ideal seria existir um professor de Educação Física nas escolas, pois se sentiam despreparados para ministrar as aulas. Verificou-se também que os professores apenas aplicavam brincadeiras de rua, modalidades esportivas de forma não estruturada e organizada. No entanto, o autor alerta que é importante termos cuidado com a afirmação de que o profissional habilitado em Educação Física ministraria melhores aulas do que o professor unidocente. $\mathrm{O}$ autor destaca que o importante é oferecer uma educação adequada aos escolares e que o professor polivalente pode se especializar em Educação Física Escolar e ministrar aulas desse componente curricular 
com qualidade e competência igual ou superior ao professor licenciado na área.

Indo de encontro ao descrito pelas professoras nos estudos anteriormente citados, um estudo de Silva e Krug ${ }^{4}$, que analisou o Projeto Político Pedagógico dos cursos de licenciatura em Educaçáo Física e em Pedagogia com habilitação para as séries iniciais da Universidade Federal de Santa Maria, aponta que o curso de Pedagogia deveria proporcionar a seus acadêmicos melhores instruções sobre a disciplina de Educação Física, pois todo currículo conta apenas com uma disciplina de carga horária de 60h. Sendo assim, embora os professores unidocentes com habilitaçâo em pedagogia estejam amparados legalmente, não estão preparados para atuarem no ensino da Educação Física.

O fato é que, independentemente do profissional que esteja atuando, a Educação Física Escolar precisa ser revista não apenas nas séries iniciais, a fim de contemplar os alunos com o máximo de benefícios que a prática do exercício e o conhecimento dos esportes, jogos e demais conteúdos possam proporcionar, pois, como coloca Santim ${ }^{40}$, a história da Educação Física parece arrastar-se de maneira secundária, recebendo de outras instâncias o aval de suas funçóes, sendo que atualmente possui um perfil deficiente, parcial, instrumental e serviçal. Não se pode negar a importância de trabalhar o aspecto motor no decorrer da infância, sendo, desta forma, a escola, enquanto meio educacional, responsável por oferecer oportunidades de vivências motoras ${ }^{41}$, ainda mais nas séries iniciais, onde a prática de movimento torna-se um caminho para que a criança compreenda melhor suas habilidades e consiga adaptá-las a outras atividades dentro e fora da escola ${ }^{6}$.

\section{Conclusão}

Em nosso estudo, diferenças estatisticamente significativas só foram encontradas no teste de agilidade para o sexo masculino, com maior percentual de resultados insatisfatórios por alunos da rede estadual, e na avaliação da força de membros superiores, também para o sexo masculino, porém com maior percentual de escolares da rede municipal com resultados abaixo do recomendável. No entanto, foi possível observar que, com exceção da força de membros superiores, para ambos os sexos, e velocidade, para o sexo feminino, nas demais avaliaçóes há um maior percentual de alunos da rede estadual com resultados insatisfatórios.

Cabe ressaltar que, de uma forma geral, os escolares avaliados apresentaram elevados percentuais de índices insatisfatórios em todas as valências avaliadas. Este pode ser um grave indicativo de que, independentemente do profissional que esteja atuando nas séries iniciais, a
Educação Física escolar está deixando de trabalhar valências importantes no desenvolvimento destes escolares e precisa ser repensada e reformulada, a fim de que proporcione um nível satisfatório de esforços físicos, buscando a melhora das capacidades físicas, tanto as de desempenho motor como as relacionadas à saúde, buscando proporcionar o máximo de benefícios a estes alunos.

\section{Referências}

1. Brasil. Lei n. 9.394, de 20 de dezembro de 1996. Estabelece as Diretrizes e Bases da Educação Nacional. Presidência da República Federativa do Brasil [Internet] [citado em mar. 2013]. Disponível em: http://www.planalto.gov.br/ CCIVIL/LEIS/19394.htm

2. Silva Filho MF, Pereira RS. Educação física e professores polivalentes: o caso das escolas públicas municipais de Várzea Grande. Rev. Mackenzie Educ. Fís. Esporte. 2012;11(2):161-87.

3. Rio Grande Do Sul. Lei n. 8.747, de 21 de novembro de 1988: dispóe sobre o Quadro de Carreira, o Quadro em Extinção e as gratificaçóes do Magistério Estadual, dando outras providências. Sistema LEGIS. Porto Alegre. 21 nov. 1988.

4. Silva MS, Krug HN. A formação inicial de professores de educação física e de pedagogia: um olhar sobre a preparação para a atuação nos anos iniciais do ensino fundamental. Lect. educ. fís. Deportes. 2008;13(123).

5. Martins L, Felker MFC. Estudo diagnóstico sobre a educação física nas escolas públicas nas séries iniciais de ensino fundamental no município de Arroio do Sal/RS. Cinergis. 2008;9(2):1-14.

6. Etchepare LS, Pereira EF, Zinn JL. Educação física nas séries iniciais do Ensino Fundamental. REVDEF. 2003;14(1): 59-66.

7. Meurer AC, Pereira EF. Epistemologia da prática pedagógica na Educação Física nas séries iniciais do ensino fundamental. Lect. educ. fís. Deportes. 2005;10(84).

8. Freire JB. Educação de corpo inteiro: teoria e prática da Educação Física. 4a ed. São Paulo: Scipione; 1997.

9. Santos DF. Perfil dos Programas de Educação Física Escolar [trabalho de conclusão de curso]. Porto Alegre: Universidade Federal do Rio Grande do Sul, 2012.

10. Nahas, M. V. Atividade Física e Qualidade de Vida. 2a ed. Londrina: Midiograf, 2001.

11. Queiroga MR. Testes e medidas para avaliação da aptidão física relacionada à saúde em adultos. Rio de Janeiro: Guanabara Koogan; 2005.

12. Guedes DP. Implicaçôes associadas ao acompanhamento do desempenho motor de crianças e adolescentes. Rev bras educ fís Esporte. 2007; 21(esp.):37-60.

13. Twisk JW, Kemper HC, Van Mechelen W. Tracking of activity and fitness and the relationship with cardiovascular disease risk factors. Med Sci Sports Exerc. 2000;32(8):1455-61. 
14. Arruda GA, Oliveira AR, Harami GH, Greguol M, Fernandes RA. Avaliação da composição corporal e desempenho motor referenciada por normas e critérios em meninas e meninos. R Bras Ci e Mov. 2010;18(2):50-7.

15. Verardi CEL, Lobo APS, Amaral VE, Freitas VL, Hirota VB. Análise da aptidão física relacionada à saúde e ao desempenho motor em crianças e adolescentes da cidade de Carneirinho-MG. Rev. Mackenzie Educ Fís Esporte. 2007;6(3):127-134.

16. Christensen LB. Experimental methodology. 2a ed. Boston: Allyn/Bacon; 1980.

17. Associaçáo Brasileira de Empresas de Pesquisa. Critério de Classificação Econômica Brasil; 2003.

18. Projeto Esporte Brasil [Internet] [citado em jun. 2012]. Disponível em: http://www.proesp.ufrgs.br

19. Luguetti CN, Ré AHN, Böhme MTS. Indicadores de aptidão física de escolares da regiáo centro-oeste da cidade de São Paulo. Rev bras cineantropom desempenho hum. 2010;12(5):331-7.

20. Borges AF, Borim JP, Marco A. Avaliaçáo de indicadores antropométricos e neuromusculares de jovens escolares do ensino fundamental do interior paulista. Motriz. 2010;16(2):326-37.

21. Barbosa CAG, Marola Jr A, Cardoso APM, Bianconsini F, Pereira JC, Oliveira LC; Silva RM. Comportamento do crescimento e desenvolvimento físico de crianças de escola pública e particular. Motriz. 2008;14(4):505-12.

22. Cruz EM. Estudo do Salto Vertical: Uma análise da relação de forças aplicadas [dissertação]. Campinas: Universidade Estadual de Campinas; 2003.

23. Barbanti V J, Amadio AC, Bento JO, Marques AT. Esporte e atividade física: integração entre rendimento e qualidade de vida. Sáo Paulo: Manole; 2002.

24. Miyasike-Da-Silva V, Villar R, Zago AS, Polastri PF, Gobbi S. Nível de agilidade em indivíduos entre 42 e 73 anos: efeitos de um programa de atividades físicas generalizadas de intensidade moderada. RBCE. 2002;23(3):65-79.

25. Palandrani Junior V. Perfil físico e nível de atividade física em adolescentes escolares da rede pública de ensino. $6^{a}$ amostra acadêmica UNIMEP. Piracicaba; 2008.

26. Lucca C, Guerra TS. A influência da condição socioeconômica sobre o desempenho de velocidade em crianças de 9 e 10 anos de idade. Movimentum: Rev Dig Educ Fís. 2006;1.

27. Gallahue DL, Ozmun JC. Compreendendo o desenvolvimento motor: bebês, crianças, adolescentes e adultos. São Paulo: Phoerte; 2001.
28. Guedes JERP, Guedes DP. Características dos programas de educação física escolar. Rev paul educ fís. 1997;11(1):49-62.

29. Carniel MZ, Toigo AM. O tempo de aprendizagem ativo nas aulas de educação física em cinco escolas particulares de Porto Alegre, RS. Rev Bras Pesqui Educ Ciênc. 2003;3(3):23-33.

30. Hino AAF, Reis RS, Añez CRR. Observação dos níveis de atividade física, contexto das aulas e comportamento do professor em aulas de educação física do ensino médio da rede pública. Rev bras ativ fís saúde. 2007;12(3):21-30.

31. Simons-Morton BG, Taylor WC, Snider SA, Huang IW. The physical activity of fifth-grade students during physical education classes. Am J Public Health. 1993;83(2):262-4.

32. Nemet D, Pantanowitz M, Eliakim A. Physical education in Israeli middle schools: a time for action. Harefuah. 2007;146(4): 265-8.

33. Moroz PA. A utilização do tempo nas aulas de educação física escolar do ensino fundamental em escolas privadas e públicas do município de Alvorada, RS [trabalho de conclusão de curso]. Canoas: Centro Universitário La Salle; 2006.

34. Betti M, Zulliane LR. Educação Física Escolar: uma proposta de diretrizes pedagógicas. Rev. Mackenzie Educ Fís Esporte. 2002;1(1):73-81.

35. Silva JVP, Sampaio TMV. Os conteúdos das aulas de educação física do ensino fundamental: o que mostram os estudos? Rev bras ciênc mov. 2012;20(2):106-18.

36. Guirra FJS. Mediação da Professora Generalista no trabalho corporal na Educação Infantil [dissertação]. Campinas: Universidade Estadual de Campinas; 2007.

37. Contreira CB, Krug HN. Educação Física nas séries iniciais do ensino fundamental: um estudo de caso com professores unidocentes. Lect educ fís deportes. 2010;15(150).

38. Darido SC. Educação Física de $1^{\mathrm{a}}$ a $4^{\mathrm{a}}$ série: quadro atual e as implicaçôes para a formação profissional em Educação Física. Rev paul educ fís. 2001; supl4:61-72.

39. Pereira RSA. Educação Física nas séries da fase inicial do Ensino Fundamental das escolas públicas municipais de Santo André: o olhar dos professores polivalentes [dissertação]. São Paulo: Universidade São Judas Tadeu; 2007.

40. Santin S. Educação Física "Temas Pedagógicos". Porto Alegre: EST/ESEF; 1992.

41. Canfield MS. A Educação Física nas séries iniciais: paralelo entre 15 anos. Kinesis. 2000;(23):87-102. 